\title{
Aplikasi e-KMS untuk Pendataan dan Rekapitulasi Tumbuh Kembang Balita di Posyandu Mekar Arum 18
}

\section{E-KMS Application for Data Collection and Recapitulation of Toddler Growth in Posyandu Mekar Arum 18}

\author{
${ }^{1}$ Rohmat Tulloh, ${ }^{1}$ Dadan Nur Ramadan, ${ }^{2}$ Dendi Gusnadi \\ ${ }^{1}$ Program Studi Diploma 3 Teknik Telekomunikasi, Fakultas Ilmu Terapan, Universitas \\ Telkom, Bandung \\ ${ }^{2}$ Program Studi Diploma 3 Perhotelan, Fakultas Ilmu Terapan, Universitas Telkom, \\ Bandung
}

Korespondensi: R. Tulloh, rohmatth@telkomuniversity.ac.id

Naskah Diterima: 25 September 2019. Disetujui: 19 Februari 2020. Disetujui Publikasi: 9 Maret 2020

\begin{abstract}
Mekar Arum Posyandu 18, which located in Lengkong village, has a low to moderate participation rate of mothers and toddlers, ranging from $15 \%$ to $25 \%$. Besides, the registration of growth and development of infants is done manually or handwritten by the cadre on a Kartu Menuju Sehat (KMS). KMS loss often occurs so that parents and Posyandu officials have difficulty finding a history of growth and development of infants. The purpose of this activity is to increase the number of toddlers who come to the Posyandu. Besides that, this activity intends to make it easier for parents of toddlers to get information about Posyandu activities schedules, data on children's growth and development, health information also Posyandu programs. While for Posyandu cadres, this activity can help to collect data and recapitulate the growth of children and also make it easier to reports to the village office or Puskesmas. This activity uses the technology implementation method through the creation of the Posyandu mobile application (mPosyandu). This application is an electronic KMS (e-KMS) based on Android. Electronic-based data collection methods are used as a basis for planning and implementing activities. From the measurement results, this community service activity can meet all the indicators of success. Those indicators are including, the number of mothers of toddlers who use the application reaches $90 \%$, the number of toddlers who come to Posyandu has increased to $90 \%$, all toddlers in Posyandu Mekar Arum 18 recorded digitally, the level of high satisfaction society and the level of suitability of activities that reach $100 \%$.
\end{abstract}

Keywords: Posyandu, e-KMS, toddler.

\begin{abstract}
Abstrak. Posyandu Mekar Arum 18 yang berlokasi di desa Lengkong memiliki tingkat partisipasi ibu dan balita yang terbilang rendah hingga sedang, berkisar antara 15 sampai dengan 25 persen. Selain itu pencatatan tumbuh kembang balita dilakukan secara manual atau ditulis tangan oleh kader pada selembar Kartu Menuju Sehat (KMS). Kehilangan KMS sering terjadi sehingga para orang tua dan petugas posyandu kesulitan mencari riwayat tumbuh kembang balita. Tujuan dari kegiatan ini adalah untuk meningkatkan jumlah balita yang datang ke posyandu. Disamping itu kegiatan ini ditujukan untuk memudahkan orang tua balita untuk mendapatkan informasi tentang jadwal kegiatan posyandu, data tumbuh kembang anak dan informasi kesehatan serta program-program posyandu. Sedangkan bagi kader posyandu, kegiatan ini dapat membantu untuk pendataan dan rekapitulasi pertumbuhan balita dan juga dapat memudahkan dalam pelaporan ke kelurahan atau puskesmas. Kegiatan ini menggunakan metode penerapan teknologi melalui pembuatan aplikasi mobile Posyandu (mPosyandu). Aplikasi ini merupakan sebuah elektronik KMS (e-KMS) berbasis android. Metode pendataan berbasis elektronik digunakan sebagai landasan perencanaan dan pelaksanaan kegiatan. Dari
\end{abstract}


hasil pengukuran, kegiatan pengabdian masyarakat ini mampu memenuhi semua indikator keberhasilan diantaranya, jumlah ibu balita yang memakai aplikasi mencapai 90\%, jumlah balita yang datang ke posyandu meningkat hingga 90\%, semua balita di posyandu mekar arum 18 sudah terdata secara digital, tingkat kepuasan masyarakat yang tinggi dan tingkat kesesuaian kegiatan yang mencapai $100 \%$.

Kata Kunci: Posyandu, e-KMS, Balita.

\section{Pendahuluan}

Posyandu adalah satu dari beberapa upaya pengelolaan kesehatan masyarakat yang bersumberdaya dari masyarakat itu sendiri. Artinya Posyandu dikelola secara mandiri dari dan untuk masyarakat sebagai bentuk pemberdayaan dan memberikan pelayanan kesehatan dasar bagi masyarakat (Kemenkes R.I, 2012).

Posyandu Mekar Arum 18 Terletak di Desa Lengkong, Kecamatan Bojongsoang, kabupaten bandung merupakan posyandu yang berada di komplek perumahan Kinagara Regency. Tingkat ekonomi penduduknya berada di tingkat menengah. Daerah perumahan ini sendiri berada di kontur persawahan dan daerah yang terus dipadati perumahan sehingga Posyandu Mekar Arum menjadi salah satu tempat yang memiliki fungsi penting bagi pertumbuhan anak disekitarnya khususnya di perumahan tersebut. Secara umum ada beberapa kegiatan utama yang dilakukan di semua posyandu di Indonesia khususnya Posyandu Mekar Arum 18 seperti penimbangan, pencatatan tumbuh kembang anak di bawah lima tahun (balita), pemberian vitamin dan imunisasi (Depkes R.I, 2009; Kemenkes R.I, 2009; Kemenkes R.I, 2012).

Suasana Desa Lengkong bernuansa pendidikan, dekat dengan kampus Universitas Telkom, Al-Mukhlisin 2, Al-Munawwar, MAS AL-MUKHLISIN, MAS Salafiyah AlFalah, MTSS SALAFIYAH ALFALAH. Mayoritas masyarakatnya adalah mahasiswa, pekerja, petani dan pedagang. Terdapat beberapa café/rumah makan, warung, kantor notaris, indomart dan klinik kesehatan, dan lain sebagainya. Berdasarkan data dan pengamatan, potensi sumberdaya Desa Lengkong khususnya warga Perumahan Kinagara Regency. Secara keseluruhan jumlah unit rumah/kepala keluarga penghuni perumahan Kinagara Regency adalah sebanyak 400 unit rumah/kepala keluarga.

Pada Perumahan Kinagara Regency dari 205 balita yang tercatat sebanyak 40 balita bersama ibu balita atau kurang lebih 19,5 persen aktif mengikuti kegiatan posyandu. Terjadi penurunan angka keikutsertaan masyarakat pada kegiatan posyandu. Penurunan angka ini juga terjadi di beberapa posyandu lain di Indonesia (Sihotang \& Rahma, 2016). Salah satu penyebab penurunan ini adalah penurunan kualitas pelayanan Posyandu (Fitria \& Azmi 2015; Aditya, 2017; Sihotang \& Rahma, 2016). Survey awal yang sudah dilakukan didapatkan bahwa ada dua faktor utama penyebab rendahnya angka partisipasi balita dan ibu balita pada kegiatan Posyandu Mekar Arum 18. Permasalahan pertama adalah karena kurangnya motivasi dari ibu dan balita untuk menghadiri posyandu, terlebih kegiatan di posyandu hanya dilakukan setiap satu bulan sekali. Kegiatan Posyandu biasanya diumumkan melalui media pesan online yang dikirimkan oleh RW atau RT setempat, hal ini tentu saja dirasa kurang membantu karena para ibu balita banyak yang memiliki kegiatan lain yang harus dilakukan di luar rumah. Permasalahan kedua adalah karena kegiatan Posyandu yang dianggap kurang menarik atau kurang bervariasi. Posyandu Mekar Arum 18 hanya melakukan kegiatan rutin seperti penimbangan, pencatatan tumbuh kembang anak balita, pemberian vitamin dan imunisasi. Posyandu masih dipandang sebelah mata bagi sebagian warga karena beberapa ibu masih beranggapan bahwa semua masalah kesehatan anak cukup ditangani oleh dokter anak.

Posyandu seharusnya menjadi agen utama di masyarakat yang dapat mendeteksi dini terkait kesehatan anak balita seperti stunting yang sudah menjadi 
isu nasional (Isni \& Dinni, 2020) atau kegiatan lain seperti sosialisasi program makan ikan untuk mencegah obesitas (Taslim, dkk., 2018). Warga perumahan Kinagara Regency berharap ada kegiatan tambahan yang dapat dilakukan oleh para kader posyandu, seperti praktek memasak makanan sehat, membuat bubur bayi dari bahan-bahan alami, dan kegiatan tambahan lainnya. Hal ini belum bisa dilakukan oleh para kader posyandu dikarenakan masih kurangnya pengetahuan tentang cara memasak yang benar, perhitungan gizi makanan dan sebagainya.

Permasalahan lain yang tidak kalah penting adalah semua kegiatan pencatatan oleh Kader Posyandu dilakukan secara manual atau tulis tangan diselembar kartu yang disebut Kartu Menuju Sehat (KMS). Hal ini sangat rentan terhadap kehilangan data. Permasalahan kehilangan kartu ini juga sering terjadi di posyandu lain di Indonesia (Hakim, 2015)(Windasari dan Yana, 2016). Informasi tidak bisa tersampaikan secara lengkap karena orang tua juga hanya dapat melihat tumbuh kembang anak dari KMS saja. Permasalahan kehilangan KMS sering terjadi sehingga para orang tua dan kader posyandu kesulitan mencari riwayat tumbuh kembang balita. Pencatatan ini sebagai salah satu upaya untuk memantau tumbuh kembang anak dan harus terus dilakukan agar pertumbuhan anak menjadi optimal.

\section{Metode Pelaksanaan}

Tempat dan Waktu. Kegiatan pengabdian ini dilaksanakan di Posyandu Mekar Arum 18, Komplek Kinagara Regency, RW. 17, Desa Lengkong, Kecamatan Bojongsoang, Kabupaten Bandung, bulan Agustus sampai dengan November 2019. Kondisi perumahan dapa dilihat pada gambar 1.
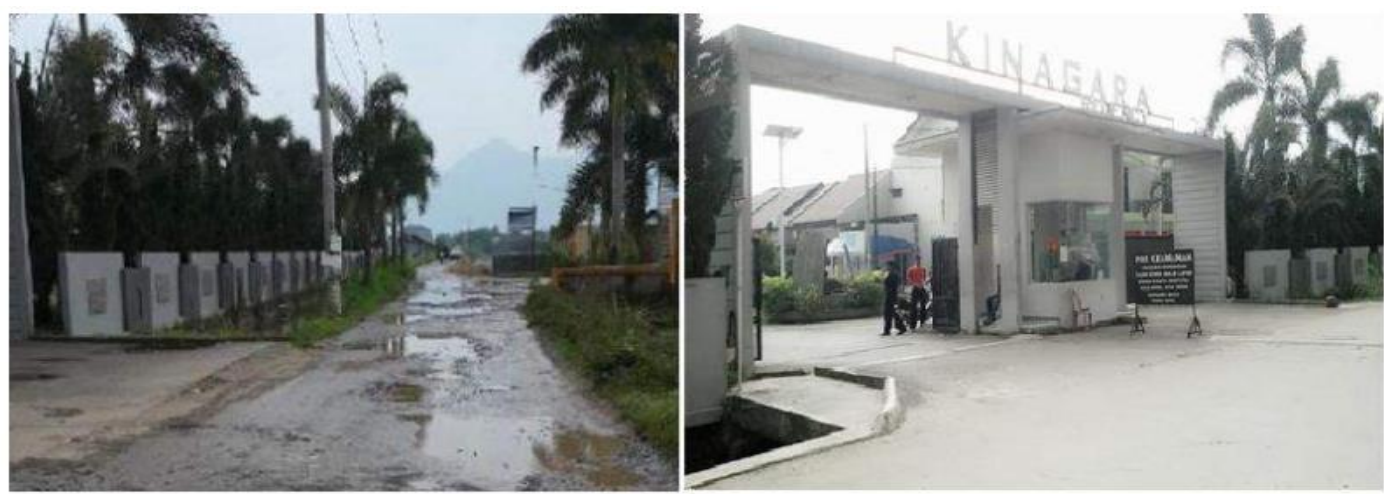

Gambar 1.Perumahan Kinagara Regency

Khalayak Sasaran. Khalayak sasaran adalah kader dan ibu balita di wilayah Posyandu Mekar Arum 18. Kader posyandu sebanyak 10 orang dan ibu balita sebanyak 120 orang. Pada gambar 2 tampak kegiatan rutin Posyandu Mekar Arum 18.
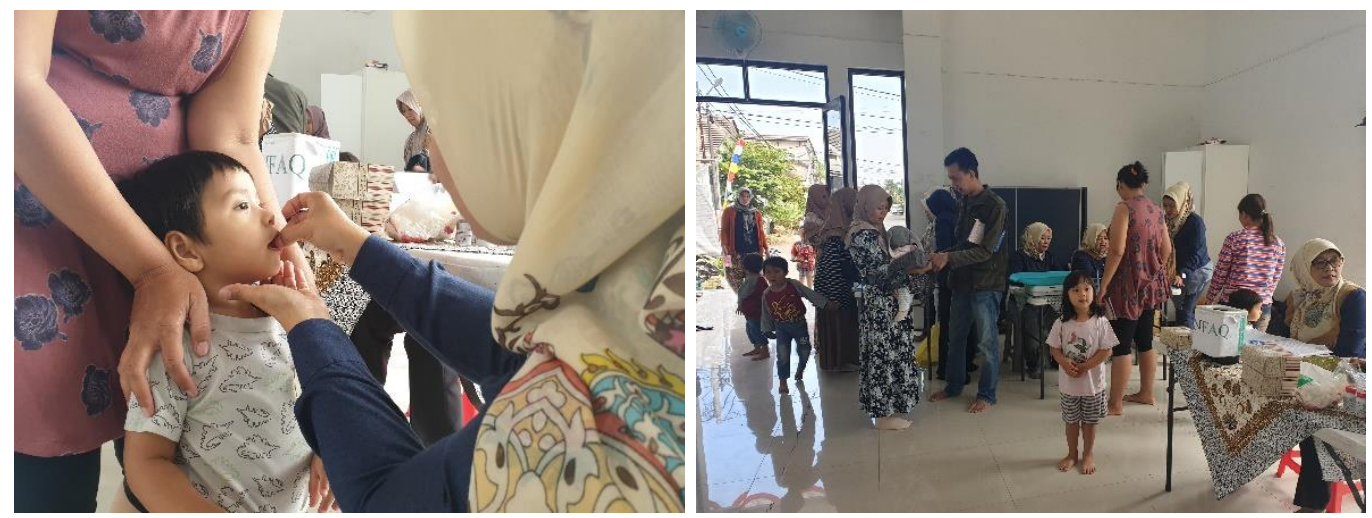

Gambar 2. Kegiatan Posyandu Mekar Arum 18 
Metode Pengabdian. Kegiatan dibagi menjadi 4 kegiatan, diantaranya persiapan dan survei awal, pembuatan Aplikasi e-KMS, Pelatihan penggunaan Aplikasi dan sebagai tambahan adalah memberikan pengetahuan dan praktek tentang pengolahan makanan, serta pendampingan selama proses instalasi, pencatatan, rekap data sampai troubleshooting aplikasi.

a. Persiapan dan survei digunakan dalam program ini, sebagai pendekatan kepada masyarakat khususnya kader posyandu dan ibu balita. Hal ini dilakukan untuk memberi pengertian akan pentingnya penerapan TIK di lingkungan sekitar khususnya pada proses pelayanan posyandu. Setelah masyarakat sadar akan pentingnya penggunaan TIK di lingkungan posyandu maka persiapan selanjutnya adalah perencanaan pembuatan aplikasi e-KMS sesuai dengan kebutuhan di lapangan. Perlu dilakuan study literatur dan survei awal terkait kebutuhan di lapangan seperti. Dari hasil survei awal didapatkan data alur kegiatan posyandu seperti tampak pada gambar 3 .

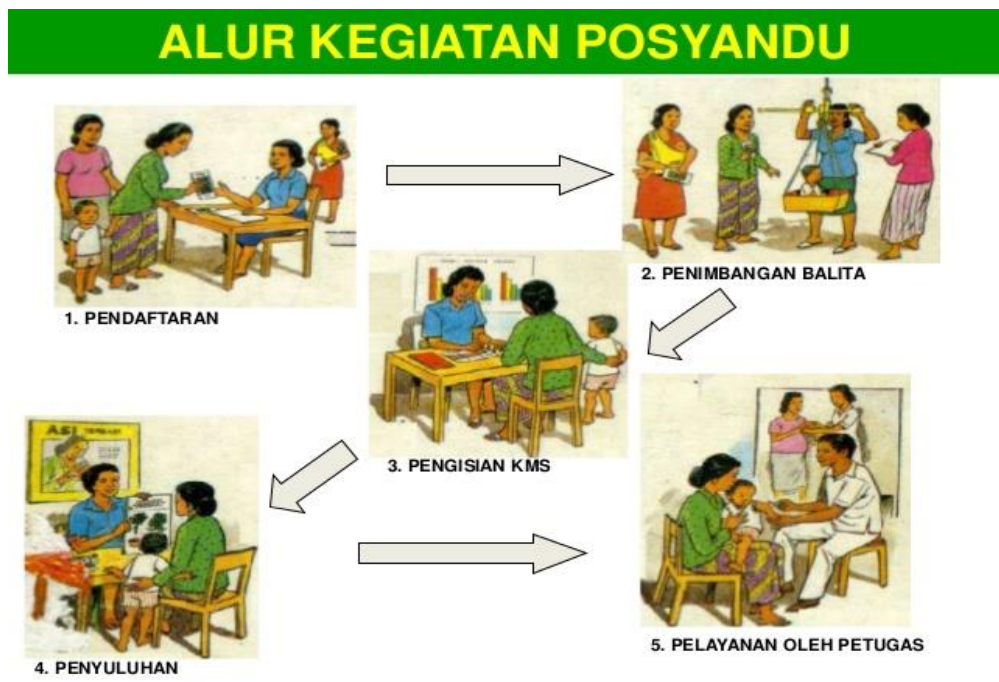

Gambar 3. Alur kegiatan posyandu

b. Perancangan dan implementasi aplikasi e-KMS. Sistem aplikasi yang akan dibuat, menggunakan bahasa android native dengan batas minimal Operating System API 17 atau android versi 4.2 (JELLY BEAN) dan target versi sdk API 27 atau android versi 8.0 (Oreo). Aplikasi android dibuat menggunakan software besutan Google yaitu android studio, untuk media penyimpanan datanya menggunakan database MySQL, kemudian untuk fitur notifikasi diintegrasikan menggunakan Firebase Cloud Messanging dan sebagai perantara data aplikasi mobile dengan database digunakan web service yang dibuat dengan menggunakan framework PhP Codeigniter. Blok diagram sistem tampak pada gambar 4.

Terdapat 3 tipe pengguna yang akan menggunakan aplikasi e-KMS, yaitu Ketua Posyandu, Kader Posyandu, dan Ibu balita. Ketua Posyandu dapat menambahkan, mengubah, mengaktifkan dan menonaktifkan akun kader Posyandu, akun Ibu balita, juga dapat mendaftarkan balita, merubah profile balita, mengisikan data pertumbuhan balita dan dapat memberikan notifikasi kepada ibu balita tentang jadwal pelaksanaan posyandu. Untuk Kader Posyandu dapat melakukan hal yang sama dengan Ketua Posyandu, kecuali fitur untuk menambahkan, mengubah, mengaktifkan dan menonaktifkan akun kader. Pada role Ibu balita dapat melihat data pertumbuhan balita yang telah diisikan oleh Ketua atau Kader posyandu, use case diagram untuk aplikasi e-KMS dapat dilihat pada gambar 5 . 


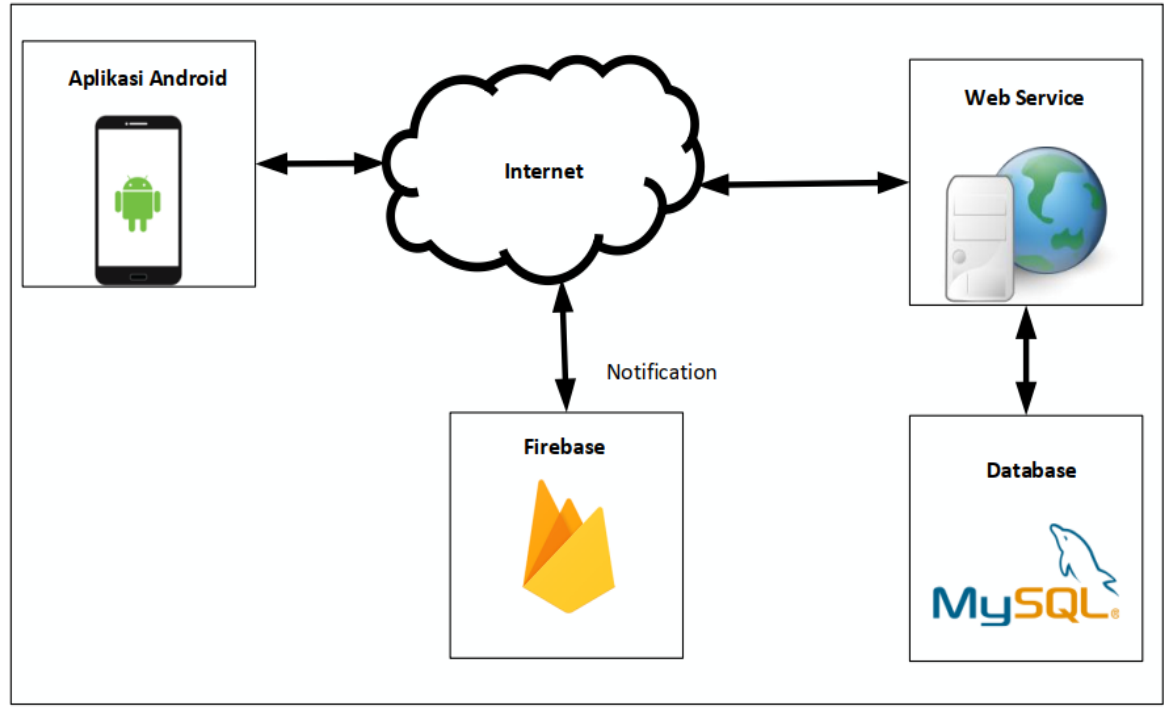

Gambar 4. Blok diagram aplikasi e-KMS

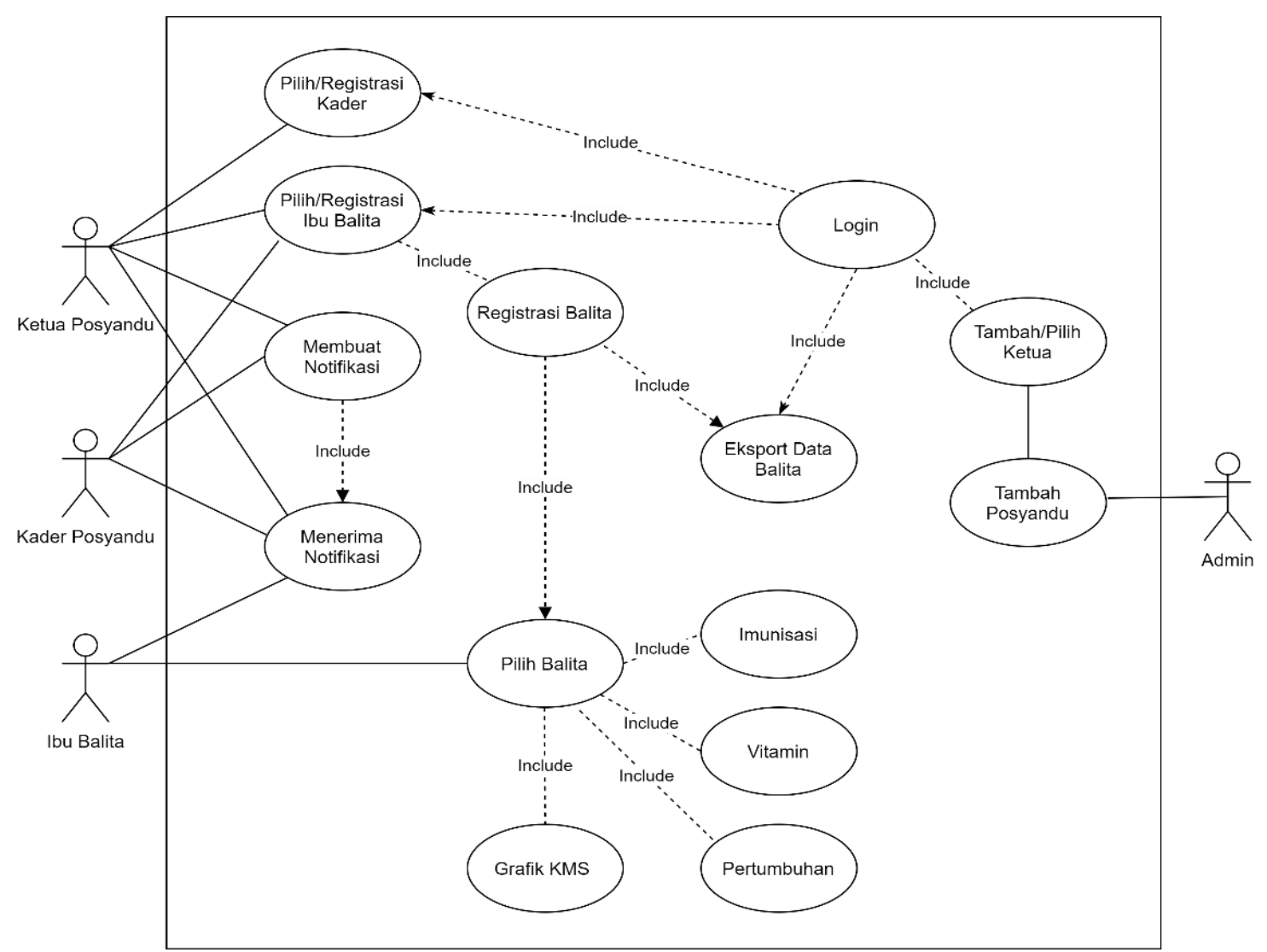

Gambar 5. Use case diagram aplikasi e-KMS

Sistem perancangan aplikasi dibuat sebelum aplikasi tersebut dibuat. Hal ini ditujukan agar pembuatan aplikasi memiliki acuan sistem (aziz dkk, 2016). Adapun sistem perancangan dari aplikasi yang dibuat ini ditampilkan pada gambar 6.

c. Pelatihan yang akan dilakukan, pertama adalah pelatihan penggunaan e-KMS yang ditujukan kepada para kader posyandu dan ibu-ibu balita agar terbiasa menggunakan aplikasi e-KMS yang disediakan. Pelatihan kedua oleh dosen pakar pengolahan makanan dengan tujuan memberikan pengetahuan dan 
praktik pengolahan makanan bergizi dan bercita rasa bagi balita dan ibu menyusui. Pelatihan ini dilakukan sebanyak 2 kali.

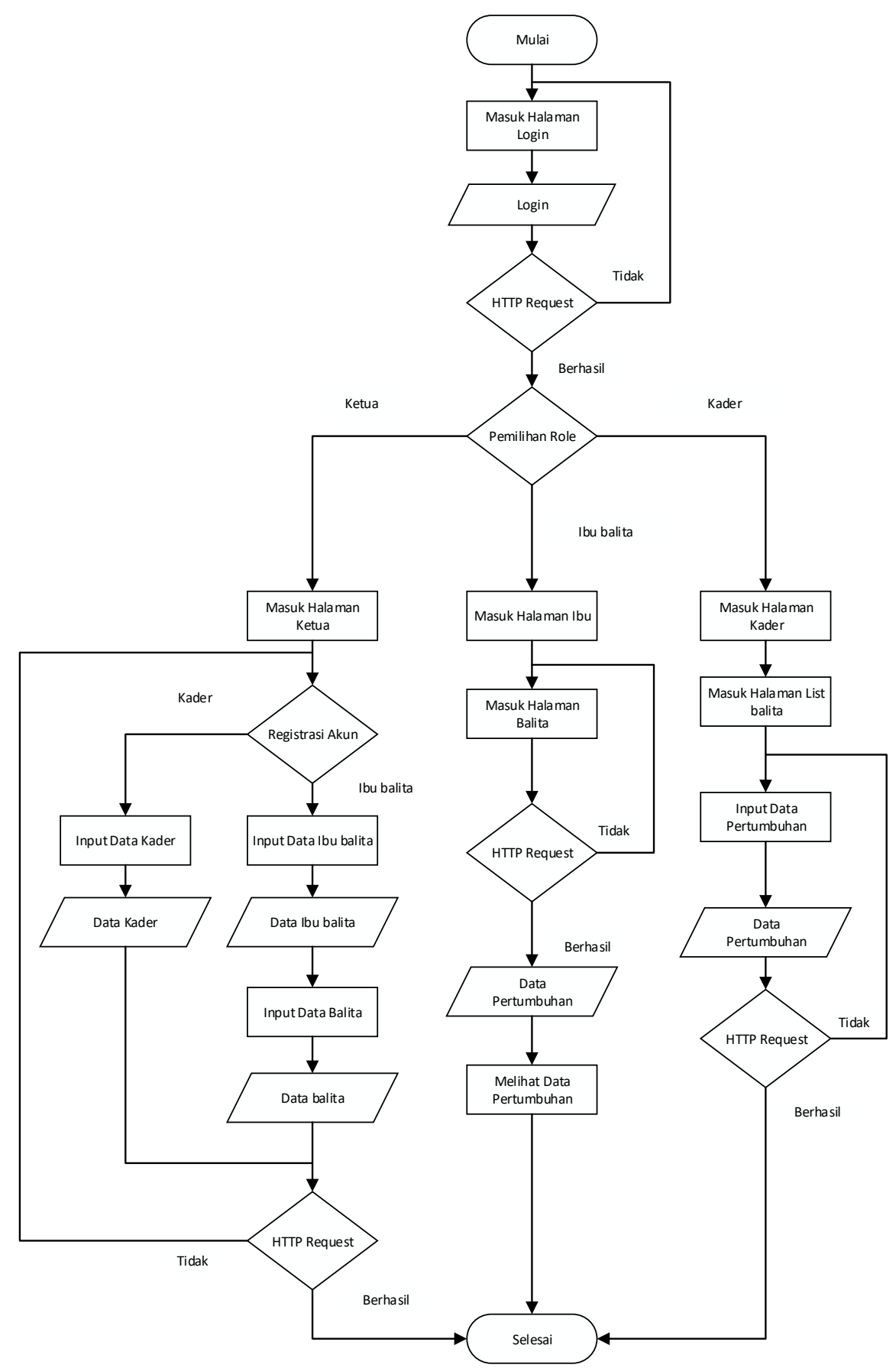

Gambar 6. Flowchart sistem

d. Pendampingan adalah kegiatan pasca pelatihan yang dilakukan oleh para dosen bersama sama dengan para kader posyandu Mekar Arum 18. Pendampingan dilakukan selama kurun waktu 3 bulan untuk melihat proses implementasi eKMS di lapangan. Pendampingan dilakukan selama proses instalasi, pencatatan, rekap data sampai troubleshooting.

Indikator Keberhasilan. Indikator keberhasilan dari kegiatan ini antara lain, (a) Jumlah kader posyandu dan ibu balita dapat menggunakan aplikasi e-KMS mencapai lebih dari 50\%, (b) Jumlah partisipasi ibu balita yang datang ke posyandu mencapai 50\%, (c) Pencatatan data balita secara digital mencapai lebih 
dari 50\%, (d) tingkat kepuasaan dan kesesuaian terhadap aplikasi dan kegiatan pengabdian masyarakat mencapai $70 \%$.

Metode Evaluasi. Evaluasi kegiatan dilakukan melalui survei di awal dan di akhir kegiatan melalui analisa data secara kuantitatif dan penyebaran kuesioner kepada para ibu balita dan kader posyandu. Kemudian dilakukan perbandingan data di awal dan di akhir kegiatan untuk melihat tingkat keberhasilaan dari pengabdian masyarakat tersebut.

\section{Hasil dan Pembahasan}

\section{A. Pelatihan dan Sosialisasi Penggunaan Aplikasi e-KMS}

Pelatihan penggunaan aplikasi e-KMS kepada para kader posyandu dan ibuibu balita, dengan tujuan agar terbiasa menggunakan aplikasi. Pada gambar 7 menunjukkan tampilan aplikasi yang sudah dibuat dan siap digunakan.
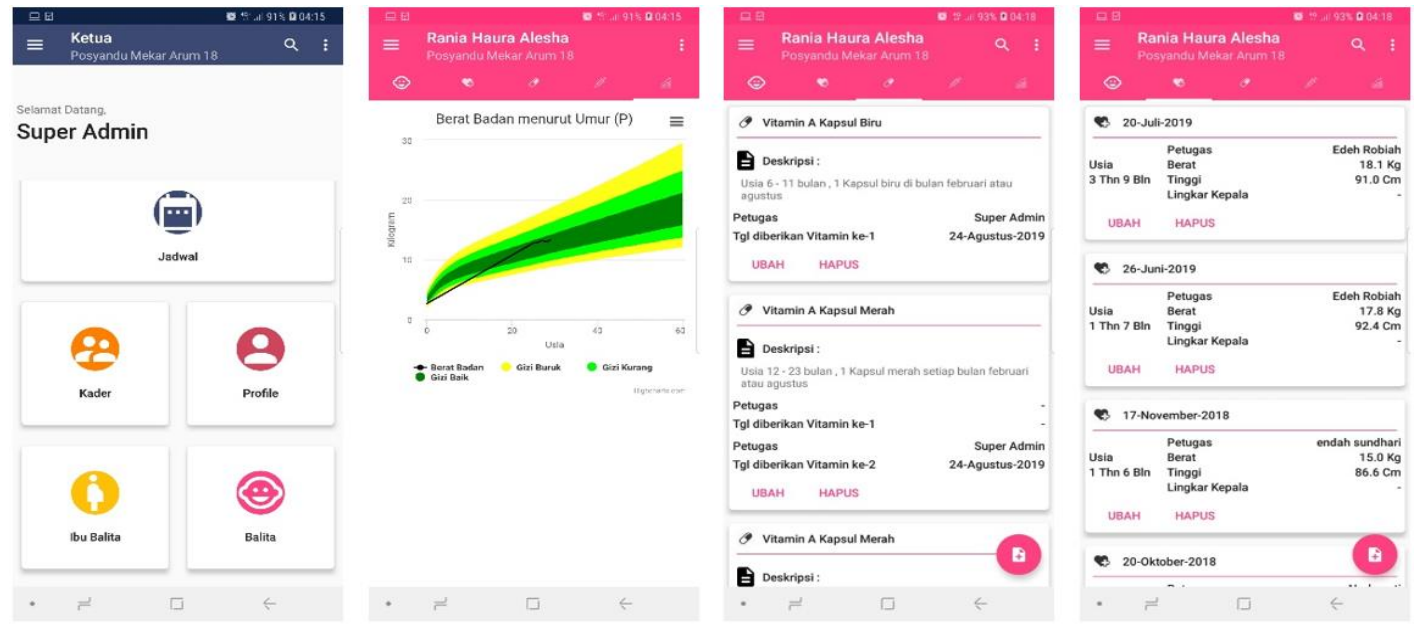

Gambar 7. Tampilan aplikasi e-KMS

\section{B. Pendampingan Kepada Kader posyandu dan Ibu Balita}

Pendampingan adalah kegiatan pasca pelatihan yang dilakukan oleh para dosen bersama sama dengan para kader posyandu Mekar Arum 18. Pendampingan dilakukan selama kurun waktu 3 bulan untuk melihat proses implementasi e-KMS di lapangan. Pendampingan dilakukan selama proses instalasi, pencatatan, rekap data sampai troubleshooting. Pada gambar 8 tampak kegiatan sosialisasi dan pendampingan kepada para kader posyandu.

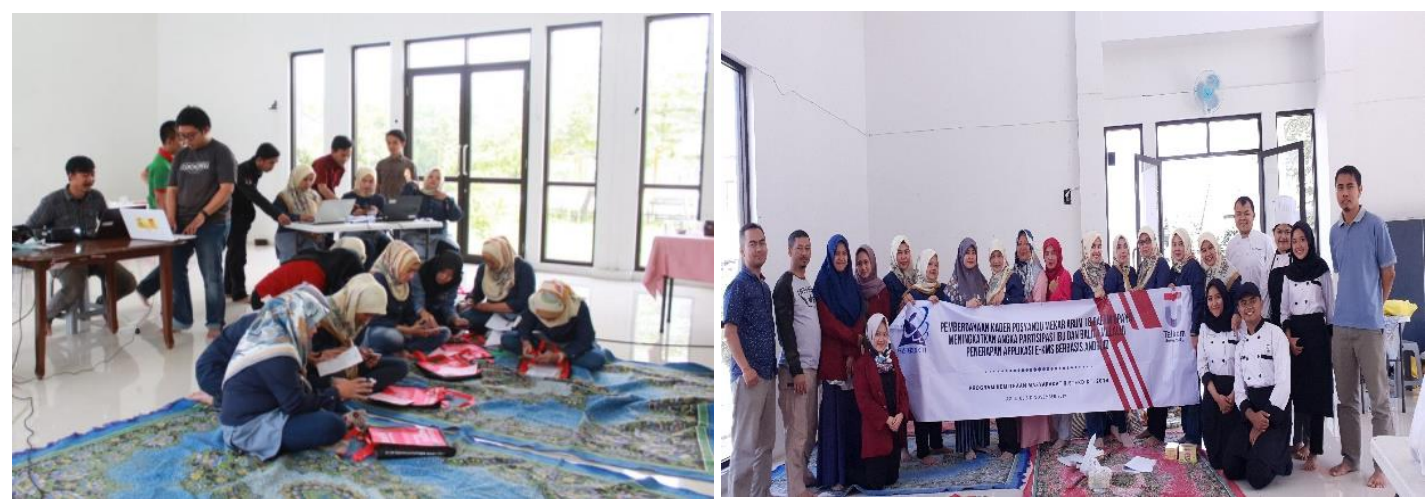

Gambar 8. Sosialisasi aplikasi e-KMS kepada kader posyandu

\section{Pelatihan Pengolahan Makanan}

Pelatihan kedua oleh dosen pakar pengolahan makanan dengan tujuan memberikan pengetahuan dan praktik pengolahan makanan bergizi dan bercita 
rasa bagi balita dan ibu menyusui, tips mengolah makanan yang sehat dan enak serta menggunakan bahan-bahan yang mudah didapat, dengan adanya kegiatan ini diharapkan para ibu balita semakin tertarik untuk datang ke posyandu, pelaksanaan praktik pengolahan makanan bergizi dapat dilihat pada Gambar 9.

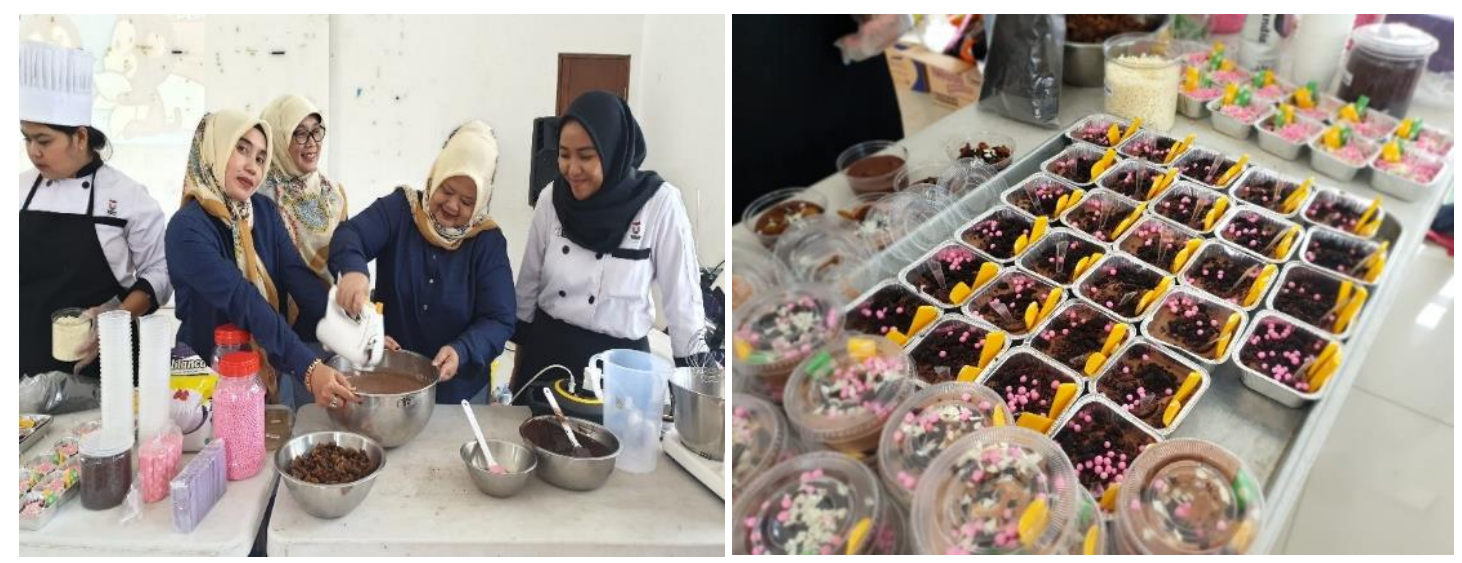

Gambar 9. Pelatihan pengolahan MPASI kepada kader posyandu

\section{Pengukuran Keberhasilan kegiatan}

Berdasarkan hasil pengukuran tingkat keberhasilan kegiatan PKM ini, didapatkan hasil seperti tampak pada tabel 1 .

Tabel 1. Pengukuran tingkat keberhasilan kegiatan pengabdian masyarakat

\begin{tabular}{|c|c|c|c|}
\hline Indikator & Sebelum & Sesudah & Cara Pengukuran \\
\hline $\begin{array}{l}\text { Jumlah ibu balita } \\
\text { yang memakai } \\
\text { aplikasi lebih dari } \\
50 \%\end{array}$ & Tidak ada & $90 \%$ & $\begin{array}{l}\text { Jumlah user aktif } \\
\text { pada aplikasi }\end{array}$ \\
\hline $\begin{array}{l}\text { Jumlah balita yang } \\
\text { datang ke Posyandu } \\
\text { meningkat } 50 \%\end{array}$ & $15 \operatorname{sd} 25 \%$ & $80 \mathrm{sd} 90 \%$ & $\begin{array}{l}\text { Daftar Hadir } \\
\text { Posyandu }\end{array}$ \\
\hline $\begin{array}{l}\text { Pencatatan data } \\
\text { digital balita oleh } \\
\text { kader posyandu } \\
\text { lebih dari } 50 \%\end{array}$ & $\begin{array}{l}\text { Data manual di } \\
\text { buku catatan }\end{array}$ & $\begin{array}{l}100 \% \text { data digital } \\
\text { balita sudah } \\
\text { tercatat di dalam } \\
\text { aplikasi }\end{array}$ & Database e-KMS \\
\hline $\begin{array}{l}\text { Tingkat Kepuasan } \\
\text { terhadap aplikasi e- } \\
\text { KMS mencapai } 70 \%\end{array}$ & Tidak ada & $\begin{array}{l}60 \% \text { sangat puas, } \\
40 \% \text { puas }\end{array}$ & $\begin{array}{l}\text { Menyebarkan } \\
\text { kuisioner ke ibu } \\
\text { balita dan kader } \\
\text { posyandu }\end{array}$ \\
\hline $\begin{array}{l}\text { Tingkat Kesesuaian } \\
\text { Kegiatan PKM dengan } \\
\text { kebutuhan posyandu } \\
\text { mencapai } 70 \%\end{array}$ & Tidak ada & $\begin{array}{l}60 \% \text { Sangat Sesuai } \\
40 \% \text { Sesuai }\end{array}$ & $\begin{array}{l}\text { Menyebarkan } \\
\text { kuisioner ke ibu } \\
\text { balita dan kader } \\
\text { posyandu }\end{array}$ \\
\hline
\end{tabular}

Pengukuran keberhasilan kegiatan kemitraan masyarakat ini dapat dilihat bahwa ada peningkatan yang cukup signifikan terhadap jumlah ibu dan balita yang mengikuti posyandu. Selain itu ibu balita yang menggunakan aplikasi juga sangat banyak yaitu sekitar 90 persen dari total balita yang tercatat. Tingkat kepuasan terhadap aplikasi e-KMS yang dibuat juga sangat baik dimana 60 persen menyatakan sangat puas dan 40 persen puas. Masih dari hasil kuisioner didapatkan bahwa 100 persen ibu balita dan kader merasa bahwa kegiatan ini sudah sesuai dengan kebutuhan posyandu. 


\section{Kesimpulan}

Berdasarkan hasil pengujian dapat disimpulkan bahwa penggunaan aplikasi e-KMS mampu mengatasi permasalahan pendataan balita yang sebelumnya masih manual dan meningkatkan angka partisipasi ibu dan balita untuk datang ke posyandu. Selain itu keberhasilan penggunaan aplikasi e-KMS ditandai dengan jumlah ibu balita yang menggunakan aplikasi mencapai 90 persen dengan tingkat kepuasan mencapai 100 persen.

\section{Ucapan Terima Kasih}

Ucapan terima kasih ditujukan kepada Direktorat Riset dan Pengabdian Masyarakat (DRPM) Kementerian Riset, Teknologi dan Pendidikan Tinggi yang memberikan dana Program Kemitraan Masyarakat (PKM) sehingga kegiatan Pengabdian Kepada Masyarakat ini dapat terlaksana pada tahun 2019.

\section{Referensi}

Aditya, T. (2017). Analisis Kualitas Pelayanan Posyandu Camar Kelurahan Poris Plawad Utara Kecamatan Cipondoh Kota Tangerang. Journal of Goverment and Civil Society. Vol.1 No. 2. pp. 203-216.

Aziz, S.B., Riza, T.A., \& Tulloh, R. (2016). Perancangan dan Implementasi Aplikasi Sistem Antrian untuk Pasien Pada Dokter Umum Berbasis Android dan SMS Gateway. Jurnal Elektro dan Telekomunikasi Terapan, [S.1.], v.2, n.1, ISSN 2442-4404. Available at: <//journals.telkomuniversity.ac.id/jett/article/view/ 95>. Date accessed: 04 feb. 2020. doi: https://doi.org/10.25124/jett.v2i1.95.

Depkes R.I. (2009). Lembar Berita Edisi Khusus Posyandu Vol XV No.1 2009, Jakarta.

Fitria \& Azmi, N. (2015). Hubungan Pemanfaatan Posyandu Dengan Status Gizi Balita di Kecataman Kota Jantho. Idea Nursing Jurnal.vol VI no.1 pp. 1-6.

Hakim, M.K. (2015). Sistem Informasi Kegiatan Posyandu Berbasis Web dan SMS Gateway (Studi Kasus Permumahan Pesona Bali), Bandung. eproceeding Universitas Telkom.

Isni, K., \& Dinni, S.M. (2020). Pelatihan Pengukuran Status Gizi Balita sebagai Upaya Pencegahan Stunting Sejak Dini pada ibu di Dusun Randugunting, Sleman, DIY. Jurnal Panrita Abdi, 4(1), 60-68.

Kemenkes, R.I. (2009). Standar Antropometri Penilaian Status Gizi Anak, Jakarta.

Kemenkes, R.I. (2012). Buku Saku Kader Posyandu, Jakarta.

Sihotang, H.M.I., \& Rahma, N. (2016). Faktor Penyebab Penurunan Kunjungan Bayi di Posyandu Puskesmas Langsat Pekanbaru Tahun 2016. Journal Endurance, Vol.2 No. 2. pp 168-177.

Taslim, N.A., Asfar, M., Angriawan, S., Yuliana, I., \& Ashari, N. (2018). IbW-CSR IDI Kota Makassar, Menuju Makassar Sehat melalui Peningkatan Konsumsi Ikan, Sayur dan Buah. Jurnal Panrita Abdi, 2(2), 127-134.

Windasari, I.P., \& Yana, R.R. (2016). Aplikasi Mobile Kartu Menuju Sehat (M-KMS), Jurnal Sistem Komputer. Vol.6, No.2. November 2016.

Penulis:

Rohmat Tulloh, Program Studi Diploma 3 Teknik Telekomunikasi, Fakultas Ilmu Terapan, Universitas Telkom, Bandung. E-mail: rohmatth@telkomuniversity.ac.id

Dadan Nur Ramadan, Program Studi Diploma 3 Teknik Telekomunikasi, Fakultas Ilmu Terapan, Universitas Telkom, Bandung. E-mail: dadannr@telkomuniversity.ac.id

Dendi Gusnadi, Program Studi Diploma 3 Perhotelan, Fakultas Ilmu Terapan, Universitas Telkom, Bandung. E-mail: dendi@,telkomuniversity.ac.id

Bagaimana men-sitasi artikel ini:

Tulloh, R., Ramadan, D.N., \& Gusnadi, D. (2020). Aplikasi e-KMS untuk Pendataan dan Rekapitulasi

Tumbuh Kembang Balita di Posyandu Mekar Arum 18. Jurnal Panrita Abdi, (4)2, 215 - 224. 